\title{
Numerical Investigation of Timber Log-Haus Walls with Steel Dovetail Reinforcements under In-Plane Seismic Loads
}

\author{
Chiara Bedon (iD ${ }^{1}$ and Massimo Fragiacomo ${ }^{2}$ \\ ${ }^{1}$ Department of Engineering and Architecture, University of Trieste, Trieste, Italy \\ ${ }^{2}$ Department of Civil, Construction-Architectural and Environmental Engineering, University of L'Aquila, L'Aquila, Italy \\ Correspondence should be addressed to Chiara Bedon; bedon@dicar.units.it
}

Received 6 August 2017; Revised 11 November 2017; Accepted 12 November 2017; Published 28 January 2018

Academic Editor: Luigi Di Sarno

Copyright ( $) 2018$ Chiara Bedon and Massimo Fragiacomo. This is an open access article distributed under the Creative Commons Attribution License, which permits unrestricted use, distribution, and reproduction in any medium, provided the original work is properly cited.

\begin{abstract}
The paper investigates the structural response and vulnerability of timber log-haus walls under in-plane seismic loads. Careful consideration is given, in particular, to the structural efficiency of additional metal fasteners introduced within the thickness of traditional timber log-walls. Log-haus systems are in fact typically obtained by stacking multiple logs and generally used for residential or commercial buildings up to two levels. Their seismic characterization, however, still requires further investigations and studies, since current standards for timber structures (i.e., Eurocode 5 and Eurocode 8) do not provide specific recommendations for their seismic design. In this regard, the so-called "steel dovetail profiles" investigated in this paper are aimed to improve the in-plane stiffness and ultimate resistance of traditional log-walls. In particular, taking advantage of past experiments carried out on small-scale joint specimens, as well as past 3D numerical efforts for the same structural typology (unreinforced assemblies), full 3D solid models are described in ABAQUS to assess the potential of steel dovetail profiles, as well as to capture possible issues. Numerical simulations are proposed both for small-scale specimens and full log-haus assemblies, being representative of the actual loading and boundary conditions for log-haus walls as part of a real building. As such, the effects of key input parameters and main influencing aspects are emphasized. In conclusion, it is shown that the examined reinforcing technique can offer rather stable initial stiffness and ultimate resistance increase, compared to unreinforced assemblies. At the same time, several aspects should be taken into account to properly optimize their benefits.
\end{abstract}

\section{Introduction}

This paper investigates the structural response of timber log-haus walls, with careful consideration for the efficiency of steel-reinforcing dovetails aimed to improve their overall resistance under in-plane seismic loads.

In current practice, log-haus (or log-house, Blockhaus, etc.) structural systems are obtained by placing a series of timber logs, horizontally on the top of one another so as to form a log wall (Figure 1). The mechanical interaction between basic timber components and orthogonal walls, as well as between walls and interstorey floors, is then provided by simple mechanisms such as joints, carvings, notches, and contact surfaces, while the use of a metal fastener is reduced to a minimum.

In terms of design of log-haus systems, currently available standards for seismic-resistant timber structures do not provide specific analytical models and recommendations for their appropriate verification; see, for example, Eurocode 5 [1] and Eurocode 8 [2]. As a result, in the last years, some research studies have been carried out to assess and further explore the seismic performance of log-haus systems, both at a component level and at a full-scale and assembly level (see, e.g., [3-7]). Further research investigation has been dedicated over the past decades-due to the intrinsic features of log-haus systems-to their buckling performance under ordinary loads (see [8-11]). As a general outcome of earlier research studies on their seismic and buckling behaviours, it was pointed out that as far as no mechanical fasteners are used between timber logs, the resistance of these systems is mainly given by contact interactions and friction mechanisms, in which production tolerances, possible gaps, or initial geometrical imperfections can have a key role in their actual response. 

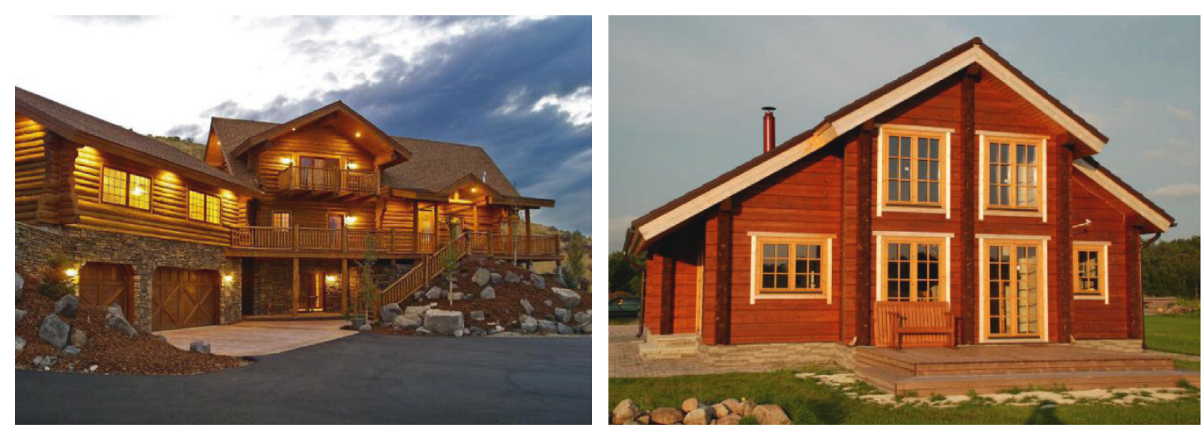

FIgURE 1: Examples of log-haus buildings.

In this paper, taking advantage of past experimental studies carried out on small-scale specimens and full log-walls [12-14], the attention is focused on the assessment of the seismic performance of steel-reinforced log-haus systems. In them, compared to traditional timber log assemblies, a coldformed metal dovetail is introduced within the thickness of a given wall, aiming to improve the interlocking between adjacent logs and to enhance their stiffness and resistance under in-plane loads like seismic inputs. The current investigation is carried out both on small-scale specimens, being representative of a portion of log wall, and on assemblies representative of the actual boundary and loading configuration for a full assembly. To this aim, full 3D finite element (FE) numerical models able to reproduce the geometrical and mechanical features of the examined specimens, as well as their actual restraint and loading conditions, are analyzed using ABAQUS [15]. Parametric FE results are then presented, giving evidence of the actual performance and expected potential for the proposed enhancing technique. Through the numerical modelling phase, major input features and assumptions are derived from [16], where an experimental and numerical study was reported to assess the overall performance of traditional, unreinforced log-haus walls under in-plane lateral loads, including small-scale as well as fullscale specimens. Compared to [16], however, special care is spent in the current investigation to explore the capacity and overall effects of the additional steel dovetails on the actual inplane lateral response of traditional log-walls. It is shown, in particular, that additional steel reinforcements in the thickness of logs can improve the actual performance of log-walls by increasing their initial stiffness and ultimate resistance. In addition, the effects of some key input features on the observed structural performances are reported and commented.

\section{Past Small-Scale Experiments: Reference Specimen Properties and Test Setup}

Quasi-static monotonic and cyclic experimental tests were carried out at the University of Trento (Italy), on a set of small-scale specimens representative of portions of log-haus structural systems. Part of these experiments included traditional carpentry joints in use, as well as log assemblies equipped with additional reinforcing profiles (see Figure 2). Major outcomes of the full experimental study can be found in [12-14].
For all the specimen types, displacement-controlled tests were aimed at assessing the response of log-haus components due to in-plane seismic loads. In the case of reinforced specimens (see Figure 2(a)), the typical assembly consisted of 4 timber logs, with C24 being the resistance class of spruce [17], $b=90 \times h=160 \mathrm{~mm}$ the nominal cross section of each $\log$, and $625 \mathrm{~mm}$ their length.

A steel reinforcement, consisting of a cold-formed dovetail profile to be installed within the thickness of a typical log wall (with $80 \times 26 \mathrm{~mm}$ the overall dimensions, $2 \mathrm{~mm}$ the thickness, and S235 the resistance class [18]), was used for the specimen labelled in this paper as "S01" (Figure 2(a)). In order to allow shrinkage deformations in timber, as well as to ease the construction phase, the length of this steel reinforcement was kept equal to $450 \mathrm{~mm}(\approx 3 / 4$ the total height of 4 overlapping logs). At the same time, no mechanical connections were used to provide the structural interaction between the steel profile and the adjacent logs, hence resulting in friction and contact mechanisms only.

A further specimen ("S02," in the following) was then also investigated. There, the same S01 section was used for the reinforcement profile, but an additional hardwood member (with D50 the resistance class [17]) was inserted within the steel dovetail to avoid local bending and premature failure of the dovetail itself (see Figure 2(b)).

A bespoke loading setup was developed (Figure 3), inclusive of an L-shaped reaction frame and a vertical restraining system, as well as two M16 threaded rods and steel springs (with $100 \mathrm{~N} / \mathrm{mm}$ stiffness). A total initial compression of $10 \mathrm{kN}$ was imposed on these rods and kept constant during the experiments in order to reproduce the effects of vertical loads acting on a log-haus wall being part of a real building (i.e., uniform compressive load of $20 \mathrm{kN} / \mathrm{m}$, in the specific case, hence a well representative of the loading configuration of a 2-storey residential building). In order to avoid possible friction mechanisms during the in-plane loading phase, low-friction Polyzene foils (i.e., FIP ${ }^{\circledR}$ technical data sheet [19]) were finally interposed between the top/bottom logs and the steel test setup.

\section{Finite Element Numerical Analysis of Small-Scale Specimens}

3.1. General Modelling Approach and Assembly. Based on small-scale experimental features and methods partly 


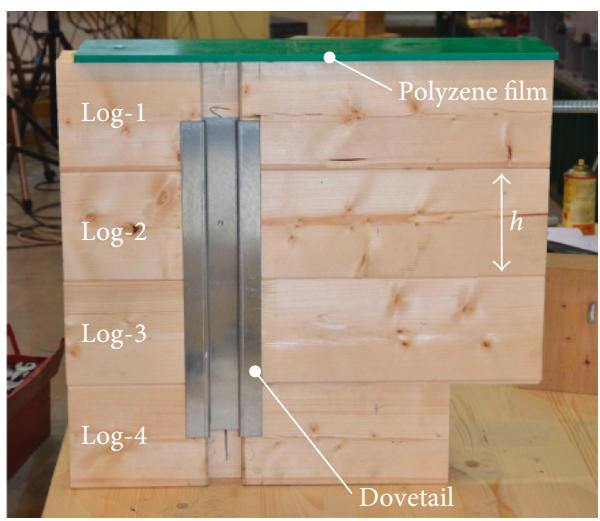

(a)

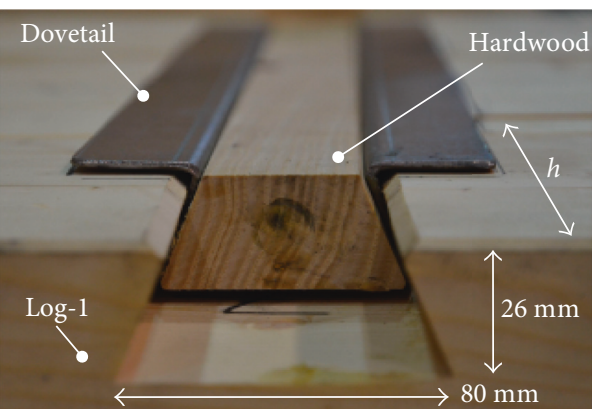

(b)

FiguRE 2: Reference experimental tests, showing (a) a typical small-scale specimen (front view) and (b) a steel dovetail reinforcement ("S02" specimen, top view), in accordance with [12-14].

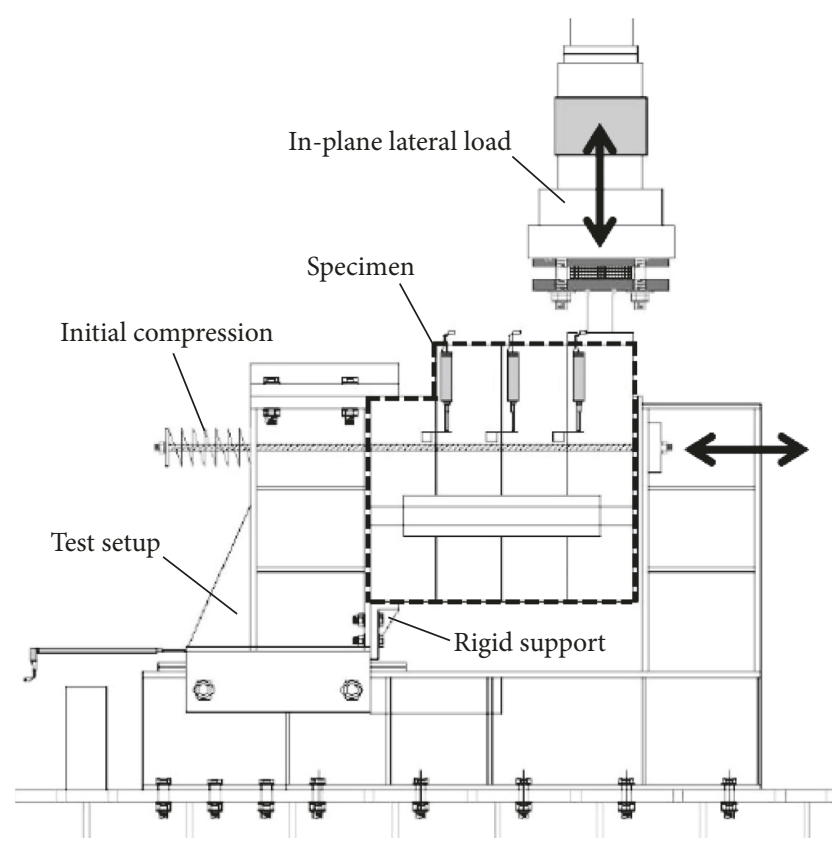

FIgURE 3: Schematic representation of test setup (front view), in accordance with [12-14].

summarized in Section 2, a finite element (FE) numerical investigation was carried out in ABAQUS, aiming to assess the monotonic performance of dovetail-reinforced specimens under a given compressive load level and an assigned in-plane seismic load. Full solid models were taken into account, based also on some past FE experiences and validations for the same structural typology (see, e.g., $[7,11,16])$.

Following the experimental features summarized in Section 2, two different FE models were developed, being representative of the S01 (M01 model) and S02 (M02 model) specimens, respectively. The difference between M01 and M02 consisted only in the presence or absence of the hardwood stiffener (and related surface mechanical interactions). The typical FE model consisted in fact of four component typologies (see Figure 4), being representative of (i) the four timber logs,

(ii) the steel dovetail reinforcement,

(iii) the hardwood dovetail stiffener (for the M02 model only),

(iv) the experimental setup (L-shaped contrast frame plus rods and springs for the application of the assigned compressive load).

In terms of specimen components, nominal geometrical properties were taken into account. Following earlier research studies, each timber log was described in the form of a regular $b \times h$ cross section, hence disregarding the presence of small protrusions and notches along the top and bottom surfaces of logs (see Figure 4(a)). In doing so, 3D solid brick elements (8-node C3D8R type and 6-node C3D6R type of ABAQUS library) were used.

Additional solid instances were also described during the modelling phase, being representative of the metal setup components, in order to correctly reproduce the actual inplane performance of the reference specimens. 8-node C3D8R-type brick elements were used, as in the case of timber logs. In addition, the steel rods and springs schematically reproduced in Figure 3 were numerically reproduced in the form of "axial" connectors with equivalent mechanical properties.

Mesh pattern and size were then set so as to maximize the computational efficiency of FE models, yet preserving the accuracy of predictions, especially in the regions of contact between the timber logs and the steel reinforcement, where local crushing phenomena were expected. To this aim, preliminary sensitivity studies and estimations were carried out on FE models representative of a single timber log and steel reinforcement assembly under in-pane shear loads by monitoring the stress evolution and distribution for the portions of timber in contact with the metal profile (see, e. g., Figure 4(c)). Five different mesh refinements were considered for timber logs by means of internal partitions and an hex-dominated sweep mesh pattern. Based on such preliminary considerations, the final FE assembly for the S01 and S02 specimens (Figure 4(b), with $M 1=10 \mathrm{~mm}, M 2=20 \mathrm{~mm}$, 


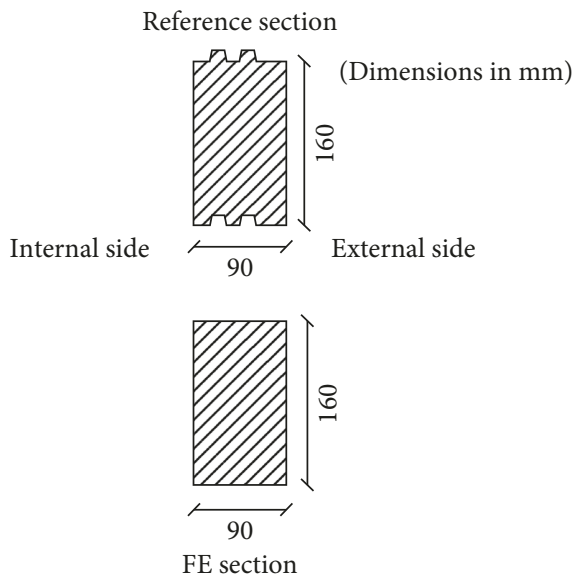

(a)

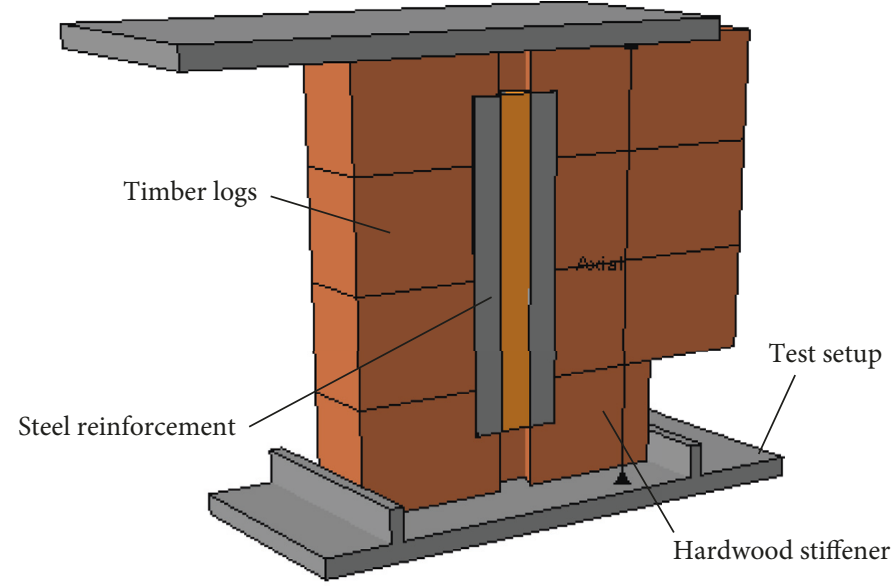

(b)

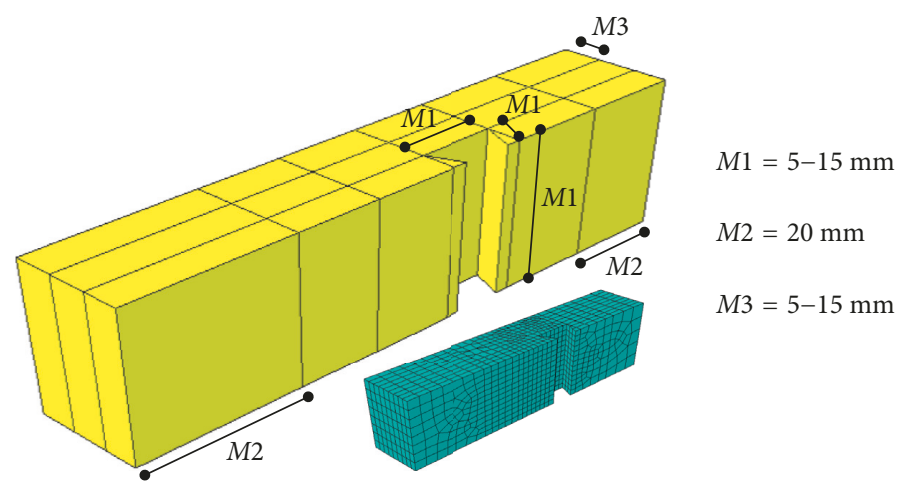

(c)

FIGURE 4: FE modelling of S01 and S02 specimens, with (a) cross-sectional features of logs; (b) full assembly (example proposed for the M02 model, with mesh pattern hidden from view); (c) mesh layout (ABAQUS).

and $M 3=10 \mathrm{~mm}$ ) consisted of 18,000 solid elements and 70,000 DOFs.

In terms of loads and boundary description for the reference FE model of Figure 4(b), the top steel plate was rigidly restrained, while for the bottom metal part, possible displacements in the vertical direction were allowed. In this manner, the initial compressive load was properly imposed-through the axial connectors-and then kept constant during the full simulation phase. The in-plane lateral loads were then assigned to the same FE assembly, in the form of a monotonic, linear increasing uniform pressure acting on the lateral face of the timber top log only, as also in accordance with the test setup of Figure 3.

3.2. Materials. Concerning the mechanical characterization of materials, careful consideration was given to the actual loading conditions of each FE model component so that simplified but appropriate constitutive laws could be used, especially for wooden members. Major efforts were in fact spent to take into account the actual mechanical properties of C24 logs-given the loading configuration of the examined specimens-as well as possible local effects due to contact mechanisms between timber logs and the steel profiles.
For C24-class spruce, an equivalent isotropic material was considered by taking into account its modulus of elasticity (MOE) in the direction parallel to grain. Based on earlier test measurements, a mean average experimental value $E_{\|}=11.56 \mathrm{GPa}$ was used (with $11 \mathrm{GPa}$ the mean nominal value recommended by [17]), while the shear modulus (with $0.69 \mathrm{GPa}$ the mean nominal value [17]) was set equal to $G=0.62 \mathrm{GPa}$ [10]. Possible failure mechanisms in timber logs were also accounted, with careful attention especially for crushing phenomena in the portions of timber in contact with the steel reinforcement, in the form of a simplified Von Mises plastic law, combined with a brittle damage model ("ductile damage" material law). Following $[10,16]$, the mean value of compressive stress in the direction parallel to grain was considered to set the yielding and ultimate stresses of C24 timber $\left(f_{c, \|, m}=\right.$ 33.59 $\mathrm{MPa}$ the experimental result). In terms of possible damage propagation due to local compression peaks in the timber logs, the "ductile damage" material option available in the ABAQUS library was also then defined. Originally intended for damage simulations in metals, the "ductile damage" constitutive law allows to account for material stiffness degradation, being detected in the material stressstrain response by damage initiation and evolution 
(including possible erosion of collapsed elements from the mesh).

In the specific case, based on past literature contributions (see, e.g., [20]), such a damage model was calibrated to account for the damaged behaviour of timber, when subjected to compression stress peaks in the direction parallel to grain. To this aim, the initial fracture strain was estimated as $f_{c, \|, m} / E_{\|}=0.005$. A linear evolution of compressive damage, up to $4 \mathrm{~mm}$ of deformation (see also [20]), was then considered.

An idealized elastoplastic mechanical law was indeed implemented for all the steel components, with $E_{s}=210 \mathrm{GPa}$ the nominal MOE, $v_{s}=0.3$ the Poisson' ratio, $\sigma_{y, s}=235 \mathrm{MPa}$ the yielding stress, and $\sigma_{u, s}=360 \mathrm{MPa}$ the ultimate value [18].

For the M02 model only, a further material behaviour was also considered for the hardwood stiffener. Due to lack of experimental calibrations at the material level, compared to C24 spruce logs, an equivalent elastoplastic law was still considered for hardwood but with nominal input parameters $\left(E_{90}=930 \mathrm{MPa}\right.$ the MOE in the direction perpendicular to the grain of D50-class timber [17] and $f_{c, 90, m} \approx f_{c, 90, k} / 0.7=8.85 \mathrm{MPa}$, being the latter value representative of the mean compressive resistance in the direction perpendicular to grain). Like in the case of timber logs, the ductile damage material option was also implemented, with $f_{c, 90, m} / E_{90}=0.01$ the failure strain initiation and a linear stiffness degradation up to $4 \mathrm{~mm}$ of local deformations ([20]).

3.3. Interactions. Based on earlier research works (see, e.g., $[7,16])$, a key role was assigned to contact interactions between specimen components. Surface-to-surface interactions were in fact implemented at the timber-to-timber and timber-to-steel interfaces. The full set of contact interactions was basically subdivided into four groups, namely, accounting for possible mechanisms among

(a) overlapping timber logs,

(b) the top/bottom timber logs and the steel substructure (where Polyzene foils were interposed),

(c) each one of the timber logs and a portion of the adjacent steel dovetail profile,

(d) the steel dovetail profile and the inner hardwood stiffener (for M02 model only).

For all these surface contact algorithms, a general penalty approach was used, with variations in the basic input parameters related to sliding only (tangential behaviour). The static friction coefficient was assumed for the (a) to (d) contact typologies listed above, which is equal to $0.5,0.2$, 0.6 , and 0.9 , respectively [7]. In the case of the (a) type interaction, in particular, the reference average value was derived from earlier experimental measurements reported in [16] for static friction tests carried out on small-scale log-haus specimens. The presence in the test setup of low-friction Polyzene foils was accounted in (b) type interactions via a 0.2 static friction coefficient, being well representative of the actual interaction between wooden members and plastic films (see, e.g., [21-24]). For the steel reinforcement-to-timber member interactions, special care was spent for the (c) and (d) interaction types, based on the high sensitivity of such frictional parameters to several factors (wood type, orientation, moisture content, strain ratio, steel surface roughness, etc.) but also on experimental observations. For the (c) mechanical contact, the static friction coefficient was in fact set equal to 0.6 , as in the case of rough steel surfaces (see, e.g., [25-27]). For the (d) type interaction, finally, a fictitious reference friction value was indeed considered, being calibrated to account for an almost total lack of possible sliding at the hardwood-to-steel dovetail interface. During the experimental assembly of the reference specimen, the hardwood member was in fact hammered within the steel profile.

In the direction perpendicular to all the surfaces involved in the same groups of contact interactions, the "hard normal" behaviour was considered so that compressive stresses could be transferred among the FE model components (i.e., as far as any kind of damage in materials occurs) and misleading overlapping effects could be avoided. Possible separation of involved surfaces when subjected to null compressive pressures, finally, was also taken into account so that the partial uplift and overturning of single logs, as well as the possible detachment of the steel dovetail reinforcement from timber logs, could be properly simulated.

3.4. Solving Approach. The typical FE analysis consisted of two sub steps. First, the initial compressive load was imposed on the specimens, via the restraining steel rods and springs, in accordance with the reference tests (see Figures 3 and 4(b), as well as comments given in Section 3.1). On the sopreloaded M01 and M02 FE models, a dynamic simulation with quasi-static increase of the in-plane shear load imposed on the top log was hence carried out in ABAQUS/Explicit, up to the attainment of a lateral displacement of $40 \mathrm{~mm}$, corresponding to a lateral drift of $0.0625 \mathrm{H}$, with $H=640 \mathrm{~mm}$ being the total height of the four overlapping logs. The latter reference amplitude for the ultimate displacement of top logs was set, at the time of the experimental study [12-14], as conventional failure configuration.

3.5. Discussion of FE Results. Generally, a rather good agreement was observed for both the FE models and corresponding test results, in terms of overall performance as well as local phenomena in each component. A loaddisplacement comparison is proposed in Figure 5, for both the specimen typologies, as obtained by monitoring the inplane lateral displacement of the top log.

As shown, the FE models proved to offer rather interesting estimations for the examined specimens, despite some scatter due to possible mechanical (i.e., material properties) or geometrical simplifications in the description of the specimen components, as well as of the test setup (i.e., grooves and tongues along the overlapping logs, presence of possible small gaps at the interface between the specimen components, and the test setup). In this sense, the availability of additional small-scale experiments on similar specimens could certainly offer further validation to the 


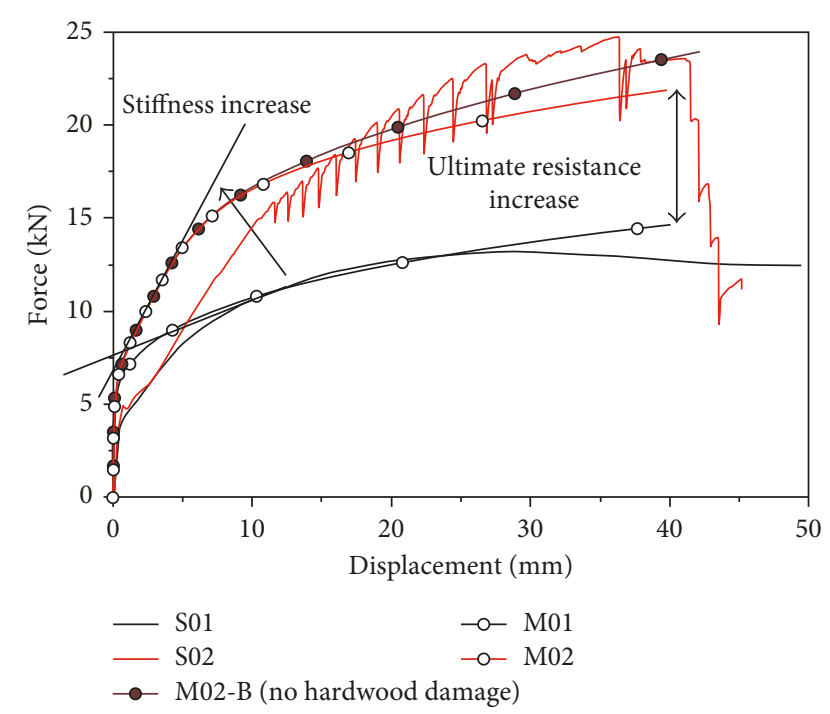

FIgURE 5: Load-displacement response of the examined specimens, as obtained from the reference experiments [12-14] and via numerical simulations (ABAQUS).

actual FE assumptions. In any case, despite the limited number of test results, from the current comparisons, it is already possible to appreciate the validity of numerical modelling features derived from past investigations on the same structural typology (i.e., [16, 28]).

Major scatter can be noticed especially in the first loading phase, when sliding and progressive uplift of logs begin (see Figure 5). As far as the measured displacements of the top log are in the order of 5-10 mm, both the M01 and M02 models tend to overestimate the actual resistance of corresponding specimens. In this sense, such a scatter could find reasonable justification in the metal reinforcement stiffness (i.e., variations in the nominal modulus of elasticity and/or thickness of the steel profile), as well as in possible tolerance gaps at the interface between the steel profile and the adjacent logs (see also [16]).

Generally speaking, from Figure 5, it can be noticed that a totally different in-plane response was observed for the S02 and M02 specimens, compared to the unreinforced S01 and M01 system. The test on the S02 system, as well as the corresponding FE model, showed in fact an increase of maximum resistance in the order of $150 \%$, compared to the S01 specimen, that is, up to $25 \mathrm{kN}$. A marked increase of initial stiffness can be also observed in the same figure, taking advantage of the hardwood stiffener, as far as the dovetail is involved in the overall resisting mechanism.

Worth of interest, in Figure 5, is finally the effect in the M02 model of possible damage evolution, due to crushing phenomena, within the hardwood member. There, the "M02B" plot is in fact obtained by considering an ideal elastoplastic behaviour for the hardwood stiffener only, in place of the damage evolution model described in Section 3.2. Despite the lack of experimental material properties for the characterization of the hardwood dovetail, in this sense, minimum variations can be noticed in terms of maximum resistance of the M02- or M02-B-stiffened specimen, even by using nominal input properties for the material damage estimation.
A further qualitative comparison is proposed for the M01 and M02 models in Figures 6 and 7, where the typical deformed shapes are shown, as numerically obtained at an imposed in-plane lateral displacement of $40 \mathrm{~mm}$ for the top $\log$. To this aim, Figures 6(c) and 6(d) also show the typical deformed shape experimentally observed at the time of past experiments, for both the specimens.

Basically, as also in accordance with Figure 5, the hardwood stiffener proved to have a key role on the overall benefits deriving from the steel dovetail alone.

Local phenomena were in fact typically observed to occur in the unreinforced steel profile, compared to the M02 specimen (see Figure 7). In the latter case, minor bending deformations only (mostly negligible) were observed in the steel profile, as a consequence of local crushing initiation in the hardwood stiffener. At the same time, crushing mechanisms were typically observed in the timber logs, in the regions of contact with the steel profile itself.

\section{Finite Element Numerical Analyses of Log-Haus Assemblies}

Based on the validation of the proposed FE model summarized in Section 3, the preliminary numerical investigation was further extended. Careful consideration, in this regard, was given to the actual behaviour of stiffened logs being part of a full 3D building.

4.1. Selected Configuration. By taking into account the typical features of log-haus assemblies in use for real buildings, additional FE models were implemented in ABAQUS. The typical FE assembly consisted of four main logs, with $2.8 \mathrm{~m}$ the nominal length and $0.09 \times 0.16 \mathrm{~m}$ cross section, plus a series of short logs (with identical cross-sectional properties), being representative of orthogonal walls intercepting the main log-wall subject of investigation. At the end of both main and orthogonal logs, the presence of "Standard" carpentry joints was properly taken into account (see Figure 8). In doing so, based on [16] as well as on average production tolerances, small gaps at the interface between orthogonal joint notches and main timber logs were also considered ( $0.5 \mathrm{~mm}$ the amplitude), being representative of key influencing parameters for the in-plane seismic response of the examined systems.

The structural efficiency of steel dovetails, placed at a distance of $0.3 \mathrm{~m}$ from the main $\log$ ends, was hence assessed.

Based on the nominal geometry of the examined assembly components, as well as on past studies (i.e., [16, 28]) and small-scale specimen analyses (see Section 3), mesh size and pattern were properly optimized at a preliminary stage of the numerical investigation so as to maximize the efficiency of FE simulations and to preserve the accuracy of predictions (i.e., evolution and distribution of stress peaks), with careful consideration especially for the regions of contact between logs and dovetails, as well as within the carpentry joints (see Figure 8(c)). The typical model hence consisted of 22,000 solid elements, with 100,000 DOFs. 


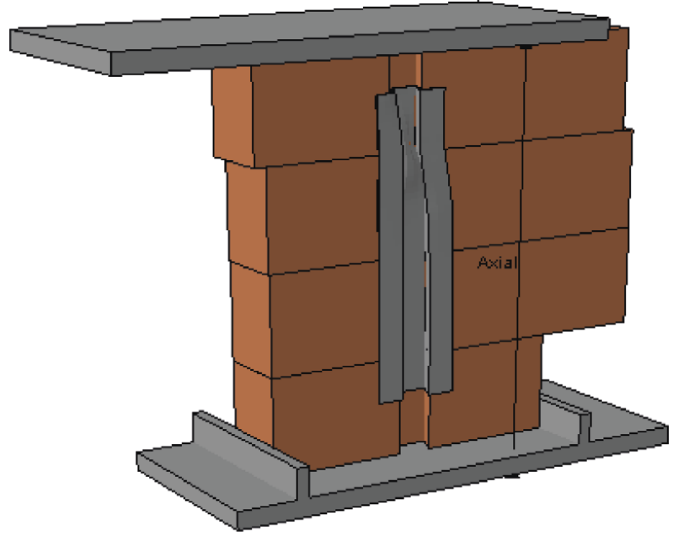

(a)

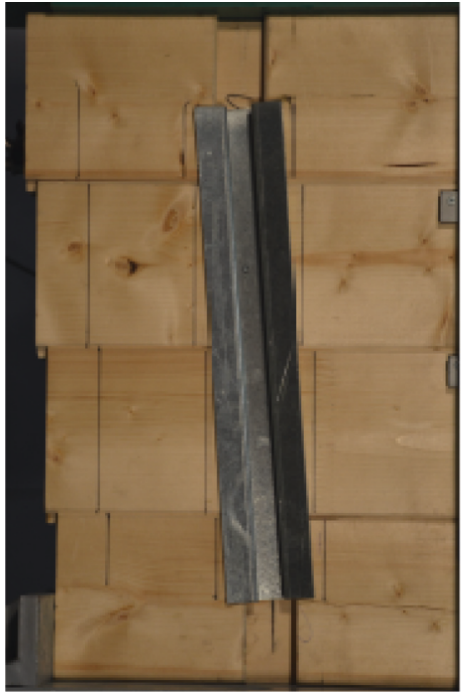

(c)

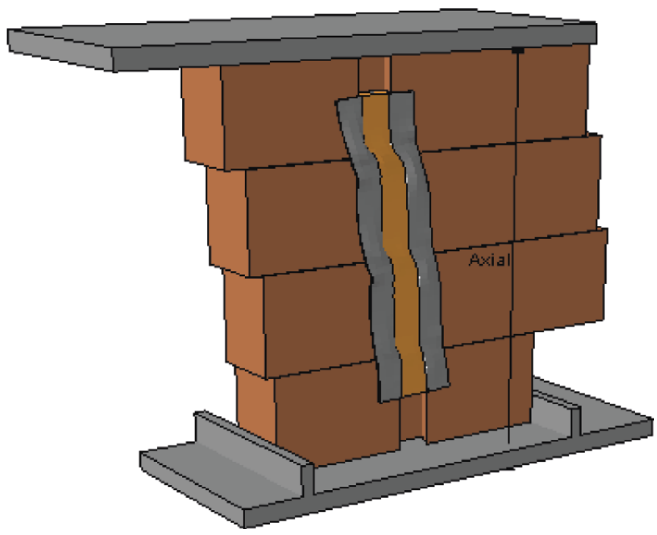

(b)

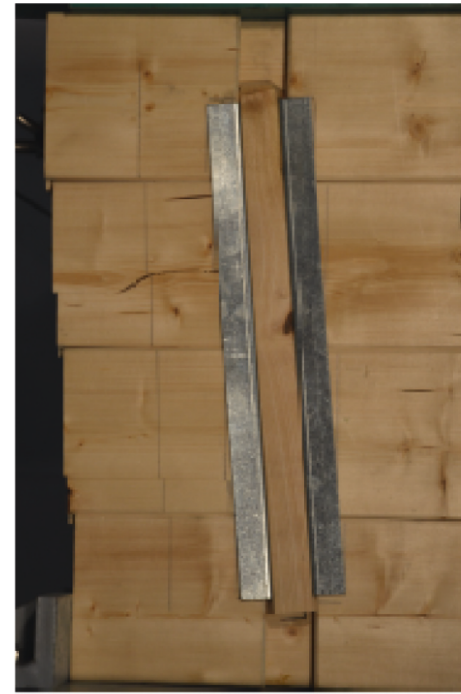

(d)

FIGURE 6: FE numerical response of (a) M01 and (b) M02 specimens, at an imposed lateral displacement of 40 mm (ABAQUS). Overall deformed configuration, with (c) and (d) evidence of the ultimate deformed shape for the S01 and S02 specimens (detail pictures from [12-14]).

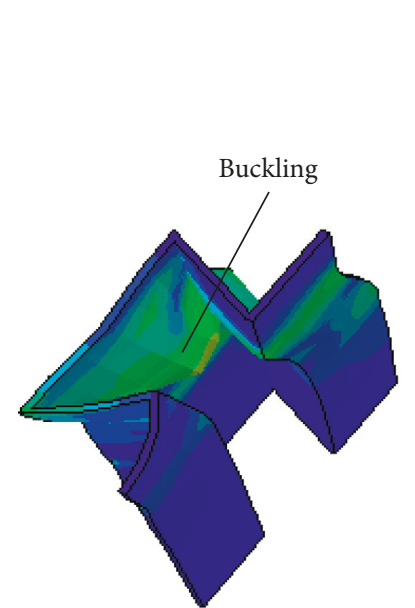

(a)

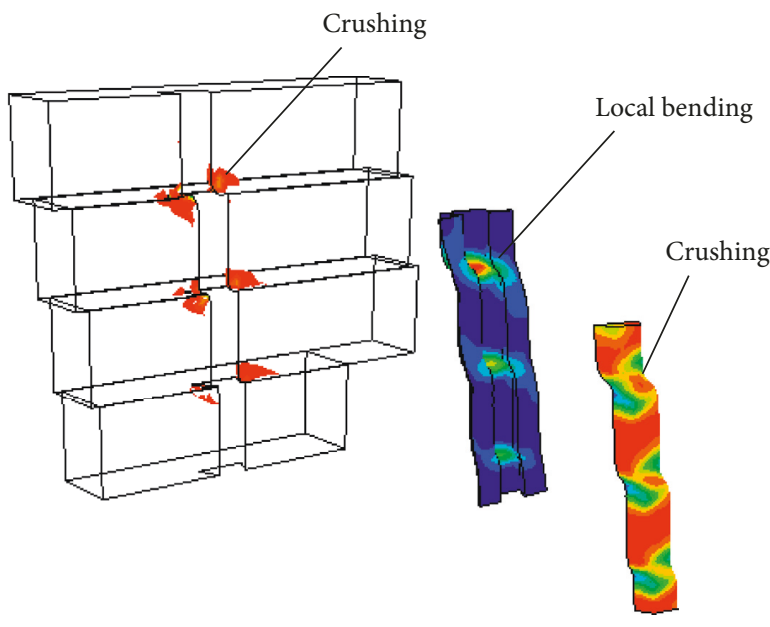

(b)

FigURE 7: FE numerical response of (a) M01 and (b) M02 specimens, at an imposed displacement of $40 \mathrm{~mm}$ (ABAQUS). Component details. 


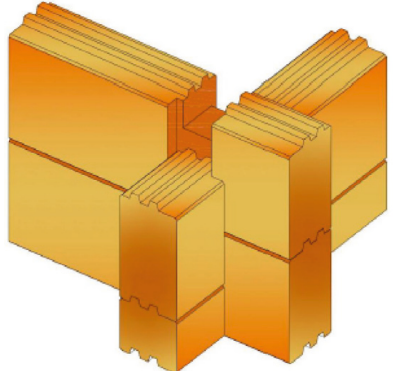

(a)

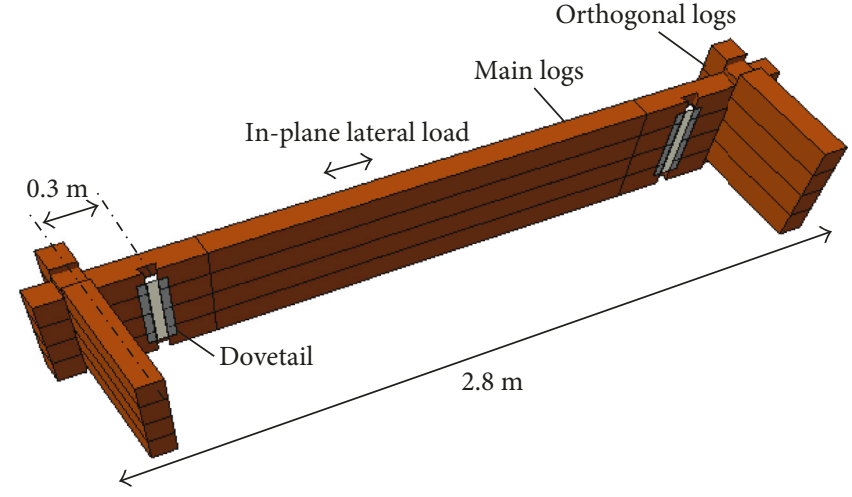

(b)

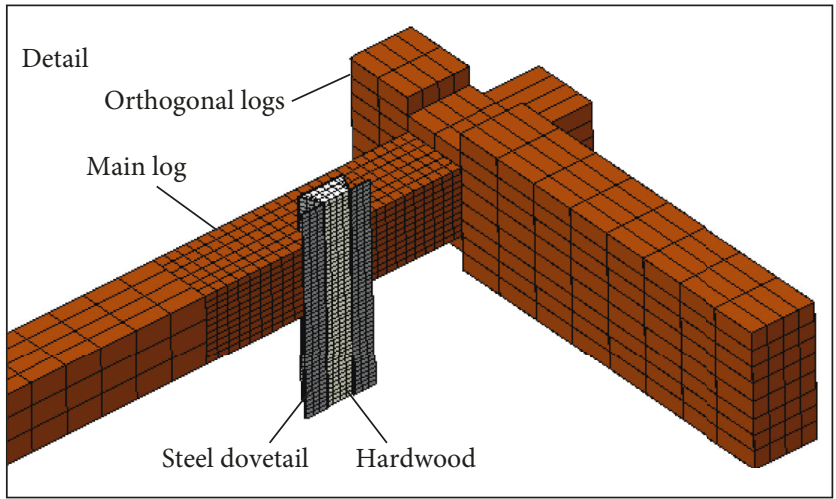

(c)

Figure 8: FE numerical modelling of log-wall assembly with steel dovetails. (a) Example of "Standard" carpentry joint and (b) overview of a typical FE model, with (c) evidence of mesh pattern, corner detail (ABAQUS).

In terms of general $\mathrm{FE}$ modelling assumptions and calibrations, compared to small-scale models presented in Section 3, the main differences consisted in the definition of boundary conditions and loading protocol for the examined log assembly. Material properties were in fact defined as in the case of small-scale specimens.

In the case of orthogonal logs only, in order to take into account their actual loading conditions as a part of the tested systems, input properties for the C24 spruce constitutive law were properly modified, being orthogonal portions of logs subjected to compressive stresses in the direction perpendicular to the grain. As such, key parameters were defined as $E_{90}=390 \mathrm{MPa}$ (nominal value of MOE in the direction perpendicular to the grain of C24-class timber [17]) and $f_{c, 90, m} \approx f_{c, 90, k} / 0.7=3.85 \mathrm{MPa}$ (mean compressive resistance in the direction perpendicular to grain [17]).

In terms of boundary conditions, the actual restraint provided by orthogonal walls was in fact properly accounted, via additional surface-to-surface contact interactions agreeing with Section 3.3 (type (a) contacts). Since a fully rigid restraint was assigned to the base logs only, possible relative displacements between overlapping and intercepting logs were in fact properly considered, in the form of relative sliding and/or separation/detachment of all the possible timber-to-timber and timber-to-steel interfaces.
Regarding the loading protocol for the so-assembled FE models, like in the case of small-scale specimens, the reference analysis consisted of two separate sub steps. Dynamic simulations with quasi-static application of loads were carried out with the ABAQUS/Explicit solver. First, a compressive vertical load was imposed on timber logs and kept constant during the in-plane lateral loading phase. In doing so, a uniformly distributed pressure was defined and applied on the full top face of upper main and orthogonal logs, being representative of the actual vertical load for residential loghaus buildings up to 2 interstorey levels. In the subsequent step of the analysis, an in-plane, linearly increasing lateral load was indeed assigned to the main top log only (i.e., uniform pressure on its lateral face) so as to reproduce the loading protocol of a monotonic seismic test for the examined assembly.

4.2. Parametric Analyses. In Table 1, a selection of FE model configurations is proposed, being representative of a part of a more extended set of analyses carried out on full 3D log assemblies with steel dovetail reinforcements. Major variations included the presence or removal of metal reinforcements, as well as the level of compressive vertical load and the resistance class of the dovetail stiffener within the steel profile. For the W02-E model, the effects of hardwood 
TABLE 1: Selected configurations for the FE parametric study.

\begin{tabular}{lccc}
\hline Model \# & Compressive load $(\mathrm{kN} / \mathrm{m})$ & Steel dovetail & Hardwood \\
\hline W01 & \multirow{2}{*}{10} & No & No \\
W02 & \multirow{2}{*}{$\begin{array}{c}\text { Yes } \\
\text { Yes (D50) }\end{array}$} \\
\hline W01-B & \multirow{2}{*}{15} & No & No \\
W02-B & & Yes & Yes (D50) \\
\hline W01-C & \multirow{2}{*}{10} & No & No \\
W02-C & & Yes & Yes (D50) \\
\hline W02-D & & No & Yes (C24) \\
W02-E & & & Yes (D50) \\
\hline
\end{tabular}

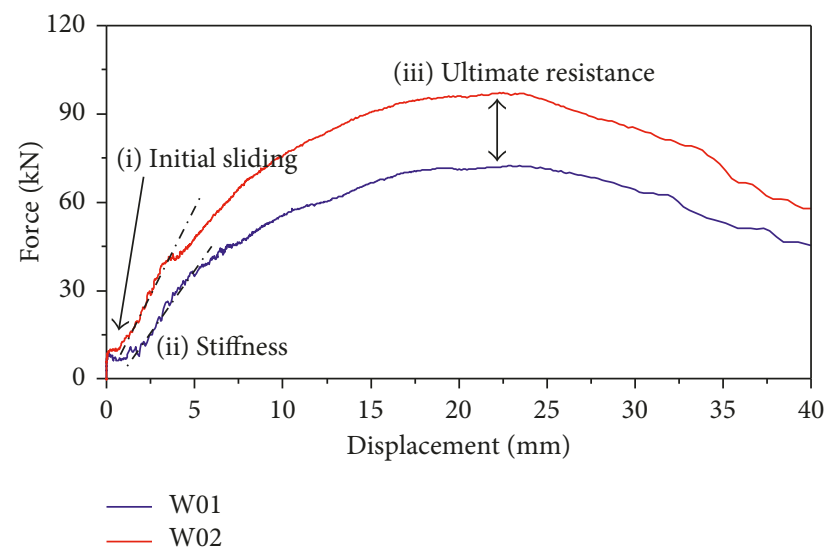

Figure 9: Load-displacement response of W01 and W02 log-haus assemblies (ABAQUS).

dovetails only were finally considered, by removing the steel components.

Basically, given a log-wall geometry and a compressive load level, the presence of steel dovetails with hardwood members proved to be associated with significant improvements for the observed structural response. In Figure 9, comparative curves are proposed for the models W01 and W02. Although the imposed lateral displacement was set up to $40 \mathrm{~mm}$, as in the case of small-scale specimens, evidence is mainly given in Figure 9 and the following plots to the first $25 \mathrm{~mm}$ of deformations $(\approx 0.04 \mathrm{H})$, being representative of the peak strength for the tested configurations.

In Figure 9, as also in accordance with earlier numerical studies, that is, [16], it can be noticed that the W01 response is associated with three specific phases. First (i), sliding occurs between the main and orthogonal logs, due to the presence of small gaps in carpentry joints. As far as all the joint gaps are closed and in contact, the joints themselves are activated and provide a certain stiffness and resistance contribution to main logs. The log assembly resistance is in fact governed by the weakest compressive or shear-resisting mechanism of "Standard" joints, while the assembly stiffness depends on a combination of multiple aspects, including the features and stiffness of carpentry joints, as well as the level of compressive vertical loads.

By comparing the W01 and W02 responses, it can be noticed that the examined reinforcement technique produces (i) reduction of initial sliding effects, due to lack of gaps at the log-to-dovetail interfaces, (ii) increase of postcontact stiffness for the log-wall assembly, and (iii) marked increase of ultimate resistance, due to combined interaction of carpentry joints, steel dovetails, and hardwood stiffeners. For the examined case study, a stiffness increase in the order of $\approx 60 \%$ of the W01 system was calculated, while an ultimate resistance increase up to $\approx 35 \%$ was estimated. As far as the maximum load-bearing capacity is attained (see Figure 9), a certain loss of resistance and stiffness can be noticed for the examined models, both in presence and in absence of steel reinforcements, for in-plane displacements larger than $25 \mathrm{~mm}$. Given the total height of $0.64 \mathrm{~m}$ for the examined log-haus system, this amplitude of in-plane deformations was found to coincide with a lateral drift in the order of $\approx 4 \%$. In this regard, it should be noticed that-as also in accordance with design standards and regulations for wooden structures-the lateral deformations of log-haus buildings under seismic loads should not exceed maximum drift values in the order of $4-5 \%$ (i.e., $\approx 120 \mathrm{~mm}$ in total, for a $3 \mathrm{~m}$ high wall) (see also [6]).

In general terms, the so-called "ultimate configuration" as well as the initial elastic response of the examined assemblies proved moreover to be highly dependent on a multitude of aspects, including

(i) the size of the joint gap and the compression load level,

(ii) the position of steel dovetails, with respect to the main $\log$ ends,

(iii) the type of carpentry joints ("Standard" type only, in the current study),

(iv) the presence of door/window openings (neglected, in this research).

For the W02 system, for example, partial crushing phenomena were noticed to occur in the hardwood profile as well as in the main logs for top log displacements in the order of $10 \mathrm{~mm}$, even with relatively low stresses in the steel dovetails (see Figures 10(a)-10(c)). The ultimate resistance of the full assembly is attained once crushing phenomena occur in the region of carpentry joints (see, e.g., Figure 10(d)).

When for the same geometrical configurations the level of compressive load modifies (see Figure 11), almost a comparable overall performance was observed for the examined models (i.e., Figure 10). In this sense, the steel profiles proved to offer rather stable benefits for the examined assembly, with initial stiffness and ultimate resistance increase being mostly independent of the compressive load level. In this regard, as also highlighted in [10], a certain compression should always be guaranteed, even in presence of seismic events.

Worth of interest, in Figure 11, is the initial stiffness increase for the examined log-haus assemblies, as far as the initial compression modifies. In particular-due to a combination of local and global mechanisms-it can be shown that major stiffness variations were observed for "B" configurations rather than for "C" systems, being subjected to minimum compressive loads only. A mostly identical resistance increase was indeed reported for them. In other 

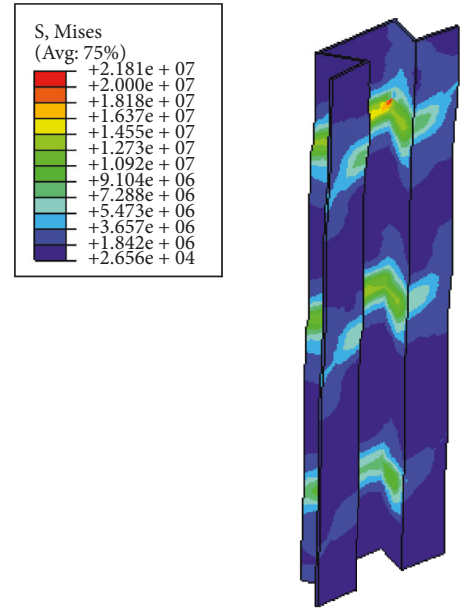

(a)

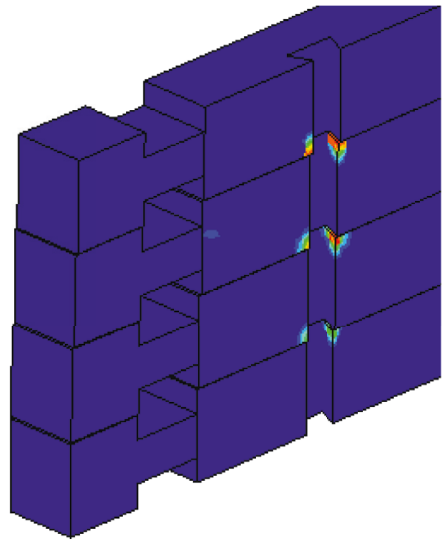

(c)
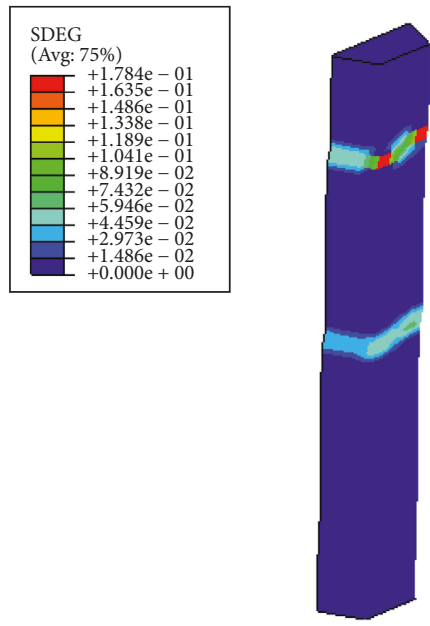

(b)
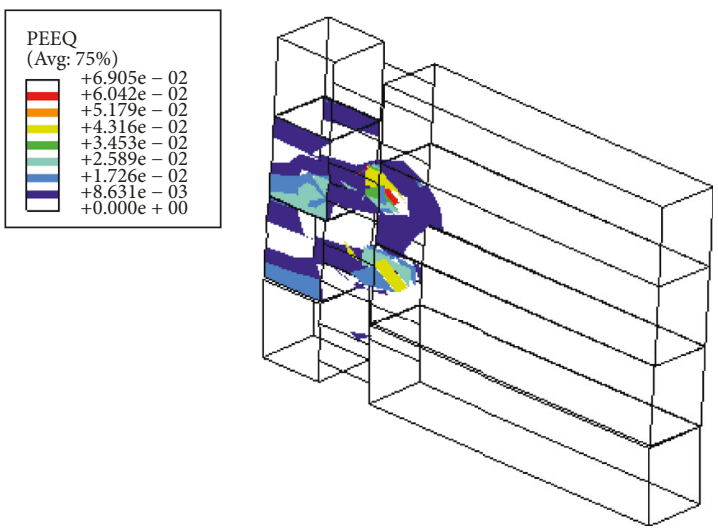

(d)

Figure 10: Damage propagation in the W02 components (ABAQUS). (a) Von Mises stresses in the steel dovetails (values in Pa), at a given displacement of $10 \mathrm{~mm}$ for the top log, with corresponding damage scenario in the (b) hardwood profiles and (c) main logs (detail). (d) Crushing phenomena in orthogonal logs (carpentry joints), at a top log displacement of $25 \mathrm{~mm}$.

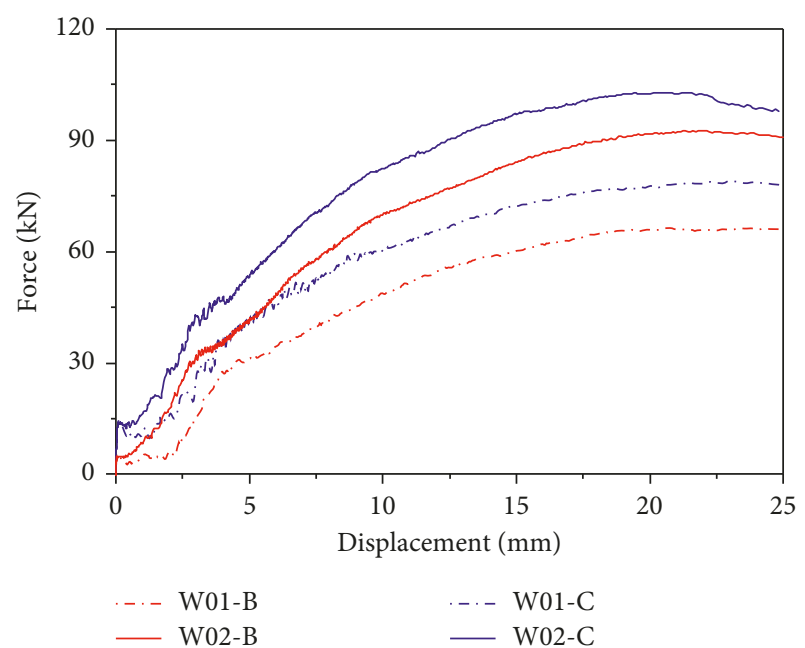

FIGURE 11: Load-displacement response of W01 and W02 log-haus assemblies (ABAQUS), depending upon the level of compressive vertical loads ("B" $=5 \mathrm{kN} / \mathrm{m}$ and "C" $=15 \mathrm{kN} / \mathrm{m}$ ). words, as far as tolerance gaps are still open (i.e., the initial stage of the in-plane load-displacement responses collected in Figure 11), the actual response of the same log-haus assemblies is related to the contribution of compressive loads and steel reinforcements. As far as the steel member stiffness is high and the compressive level is limited, partial uplift and overturning of stacked logs are prevented by the active contribution of metal dovetails. The ultimate load-bearing capacity of the same systems, however, is mainly related to local effects only, including yielding in the steel profiles and crushing in timber members. As such, the predicted resistance increase is not dependent on the compressive load level (see, e.g., Figure 11) but is mainly affected by the shear and compressive response of steel and wooden components, respectively.

As shown for both small-scale and full assembly models, in this regard, the hardwood stiffener profile proved to have a key role for the optimal performance of steel dovetails. The same timber stiffener alone, however, would not be able to offer significant improvements to the unreinforced logs. In 


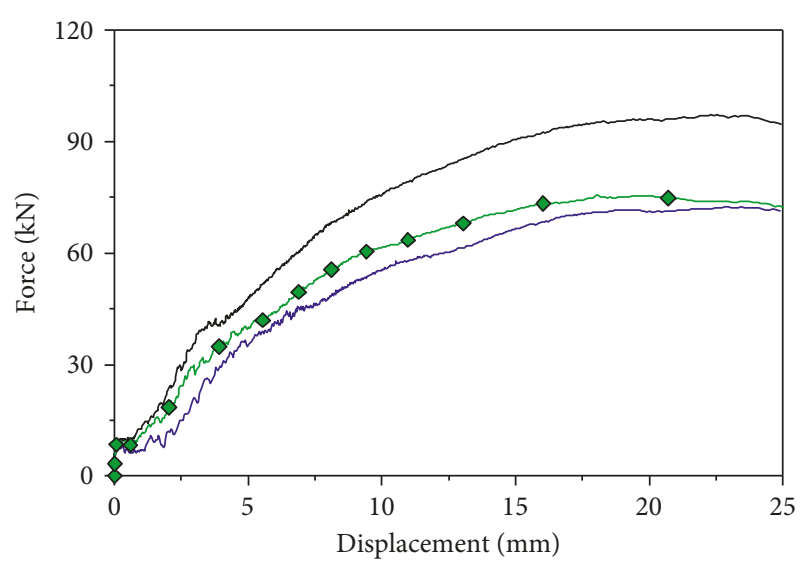

$10 \mathrm{kN} / \mathrm{m}$ compressive load

$\longleftarrow$ W01
- W02
$\curvearrowleft$ W02-E (only D50 profile)

FIGURE 12: Load-displacement response of W01 and W02 log-haus assemblies (ABAQUS), by removing the steel dovetails (W02-E).

Figure 12, for example, it is possible to notice that mostly the same load-displacement response was in fact obtained for the W02 and W02-E systems. In the latter case, the total lack of intrinsic ductility deriving from the steel inserts, in addition, could typically result in brittle and abrupt failure mechanisms in the hardwood members only (see, e.g., [10], where a brittle collapse mechanism was reported for inplane compressed log-haus walls laterally restrained by wooden hardwood members and timber pillars), with mostly negligible structural benefits for the full log-haus wall.

In general terms, finally, compared to the small-scale specimens presented in Sections 2 and 3, the FE results partly summarized in this paper for full log-haus assemblies representative of the actual loading and boundary conditions of real log systems gave evidence of a rather different behaviour. In any case, the same FE comparative results proved the feasibility and potential of the examined reinforcing technique, hence suggesting its use for the enhanced design of log-haus buildings in seismic regions.

\section{Conclusions}

In this paper, the in-plane seismic performance of log-haus walls reinforced with steel dovetail profiles and hardwood members has been investigated via finite element numerical models.

In this paper, taking advantage of earlier experimental and numerical studies, the in-plane seismic response of steel-reinforced, small-scale log specimens has been first assessed. Given a simple assembly of timber logs with a metal dovetail reinforcement inserted within the log thickness, in particular, it was shown that such a kind of steel profiles can potentially increase the initial stiffness and ultimate resistance of traditional timber logs, even based on simple contact mechanisms only. At the same time, however, it was also shown that the effectiveness of steel profiles is strictly related to the presence of additional hardwood members, being able to prevent possible premature local mechanisms in the steel sections. In addition-despite the well-promising results of small-scale specimens-the same assemblies were only partly representative of a real log-haus configuration of technical interest for design. In typical log-haus buildings, the behaviour of corner joints as well as the mechanical interactions between orthogonal logs should in fact be properly investigated.

Based on the rather close correlation between experimental and numerical results, the FE numerical study has been then further extended. In doing so, full log-haus assemblies well representative of the actual boundary and loading conditions of timber logs being part of a real building have been analyzed. Careful consideration was spent especially to assess their overall structural response, with evidence for local and global mechanisms, as well as for the effect of some influencing parameters, such as the level of initial compression, the mechanical features of hardwood cones, or the amplitude of tolerance gaps at the interface between orthogonal logs.

As shown, also in accordance with past numerical investigations and outcomes available in the literature for loghaus components and single walls, it was shown that the overall in-plane response of such systems typically depends on a combination of multiple aspects. In any case, the examined steel dovetails still proved to have beneficial effects on the seismic response of traditional log-haus walls, with marked initial stiffness and ultimate resistance increase, compared to unreinforced assemblies. Such structural benefits, for example, proved to not depend on the actual compressive level of a given log-haus assembly. In this regard, it is hence expected that the proposed enhancement technique could find application in design projects and real seismically enhanced buildings.

\section{Conflicts of Interest}

The authors declare that they have no conflicts of interest.

\section{Acknowledgments}

Part of this research project was carried out within a scientific collaboration between the authors and Rubner Haus $\mathrm{SpA}$, who is gratefully acknowledged for financial support. In this regard, Ms. Annalisa Battisti is also acknowledged for sharing data and results of the past experimental investigations carried out at the University of Trento, Italy, as well as for providing technical support in their interpretation. DPC-ReLUIS is finally acknowledged for partially funding the research activity within the framework of the "PR4-Timber structures" Italian project.

\section{References}

[1] EN 1995-1, Eurocode 5-Design of Timber Structures-Part 1: General-Common Rules and Rules for Buildings, European Committee for Standardisation (CEN), Brussels, Belgium, 2004.

[2] EN 1998-1, Eurocode 8-Design of Structures for Earthquake Resistance-Part 1: General Rules, Seismic Actions and Rules for 
Buildings, European Committee for Standardisation (CEN), Brussels, Belgium, 2004.

[3] J. M. Branco and J. P. Araújo, "Structural behaviour of log timber walls under lateral in-plane loads," Engineering Structures, vol. 40, pp. 371-382, 2012.

[4] J. M. Branco, P. B. Lourenço, and C. Aranha, "Seismic performance assessment of a timber log house," in Structures and Architecture: Concepts, Applications and ChallengesProceedings of the 2nd International Conference on Structures and Architecture, ICSA, pp. 114-121, Guimarães, Portugal, July 2013.

[5] M. Piazza, "Seismic performance of multi-storey timber buildings-Rusticasa building-Final Report, SERIES 227887 Timber Buildings Project," 2014, http://www.series.upatras.gr/dev.

[6] C. Bedon, G. Rinaldin, M. Fragiacomo, and S. Noé, "Finite element assessment of the seismic performance of three dimensional Blockhaus buildings," in Proceedings of WCTE 2016-World Conference on Timber Engineering, CD-rom, Vienna, Austria, August 2016.

[7] C. Bedon and M. Fragiacomo, "Numerical investigation of the in-plane seismic performance of timber log-haus walls with reinforced dovetails," in Proceedings of COMPDYN 2017, 6th ECCOMAS Thematic Conference on Computational Methods in Structural Dynamics and Earthquake Engineering, Rhodes Island, Greece, June 2017, paper code C16995.

[8] B. Heimeshoff and R. Kneidl, "Zur Abtragung vertikaler Lasten in Blockwänden-Experimentelle Untersuchungen," Holz als Roh-und Werkstoff, vol. 50, no. 5, pp. 173180, 1992.

[9] B. Heimeshoff and R. Kneidl, "Bemessungsverfahren zur Abtragung vertikaler Lasten in Blockwänden," Holz als Rohund Werkstoff, vol. 50, no. 11, pp. 441-448, 1992.

[10] C. Bedon, G. Rinaldin, M. Izzi, M. Fragiacomo, and C. Amadio, "Assessment of the structural stability of Blockhaus timber log-walls under in-plane compression via fullscale buckling experiments," Construction and Building Materials, vol. 78, pp. 474-490, 2015.

[11] C. Bedon and M. Fragiacomo, "Derivation of buckling design curves via FE modelling for in-pane compressed timber log-walls in accordance with the Eurocode 5," European Journal of Wood and Wood Products, vol. 75, no. 3, pp. 449-465, 2017.

[12] R. Tomasi, T. Sartori, P. Grossi, and L. Wenzell, "Blockhaus structural system: experiments on corner carpentry joints [Sistema costruttivo Blockhaus: prove su giunzioni d'angolo]," Internal Technical Report, University of Trento, Trento, Italy, 2012, in Italian.

[13] T. Giovannini, P. Grossi, T. Sartori, and R. Tomasi, "Blockhaus structural system: experiments on full-scale walls [Sistema costruttivo Blockhaus: prove su pareti a scala reale]," Internal Technical Report, University of Trento, Trento, Italy, 2012, in Italian.

[14] P. Grossi, T. Sartori, I. Giongo, and R. Tomasi, "Analysis of timber log-house construction system via experimental testing and analytical modelling," Construction and Building Materials, vol. 102, no. 2, pp. 1127-1144, 2016.

[15] Simulia, ABAQUS v.6.14 Computer Software, Dassault Systèmes, Providence, RI, USA, 2017.

[16] C. Bedon, M. Fragiacomo, C. Amadio, and C. Sadoch, "Experimental study and numerical investigation of Blockhaus shear walls subjected to in-plane seismic loads," Journal of Structural Engineering, vol. 141, no. 4, Article ID 04014118, 2015.
[17] EN 338, Structural Timber-Strength Classes, European Committee for Standardization (CEN), Brussels, Belgium, 2009.

[18] EN 1993-1-4, Eurocode 3-Design of Steel Structures-Part 1-4: General Rules-Supplementary Rules for Stainless Steels, European Committee for Standardisation (CEN), Brussels, Belgium, 2004.

[19] FIP ${ }^{\circledR}$, Technical Data Sheet-Plastic Materials, November 2017, http://www.fipitaly.it/en.

[20] C. Avez, T. Descamps, E. Serrano, and L. Léskool, "Finite element modelling of inclined screwed timber to timber connections with a large gap between the elements," European Journal of Wood and Wood Products, vol. 74, no. 3, pp. 467-471, 2016.

[21] Y. Murase, "Friction of wood sliding on various materials," Journal of the Faculty of Agriculture, Kyushu University, vol. 28, no. 4, pp. 147-160, 1984.

[22] V. Quaglini and P. Dubini, "Friction of polymers sliding on smooth surfaces," Advances in Tribology, vol. 2011, Article ID 178943, 8 pages, 2011.

[23] N. Andersson, P. Hugoson, J. Jagelčák, and S. Sökjer-Petersen, "Inclination tests to determine the static friction factor for different material combinations," MariTerm AB Technical Report, 2007, http://www.mariterm.se.

[24] A. A. Klyosov, "Slip resistance and coefficient of friction of composite deck boards," in Wood-Plastic Composites, chapter 11, John Wiley \& Sons, Hoboken, NJ, USA, 2007.

[25] W. M. McKenzie and H. Harpovich, "The frictional behaviour of wood," Wood Science and Technology, vol. 2, no. 2, pp. 139-152, 1968.

[26] C. W. McMillin, T. J. Lemoine, and F. G. Manwiller, "Friction coefficient of oven-dry spruce pine on steel, as related to temperature and wood properties," Wood and Fiber Science, vol. 1, pp. 6-11, 1970.

[27] R. Koubek and K. Dedicova, "Friction of wood on steel," M.Sc. Thesis, Linnaeus University, Växjö, Sweden, 2014, http:// www.diva-portal.org.

[28] C. Bedon and M. Fragiacomo, "Numerical and analytical assessment of the buckling behaviour of Blockhaus log-walls under in-plane compression," Engineering Structures, vol. 82, pp. 134-150, 2015. 


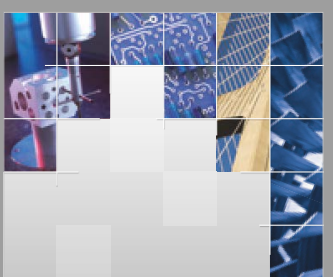

\section{Enfincering}
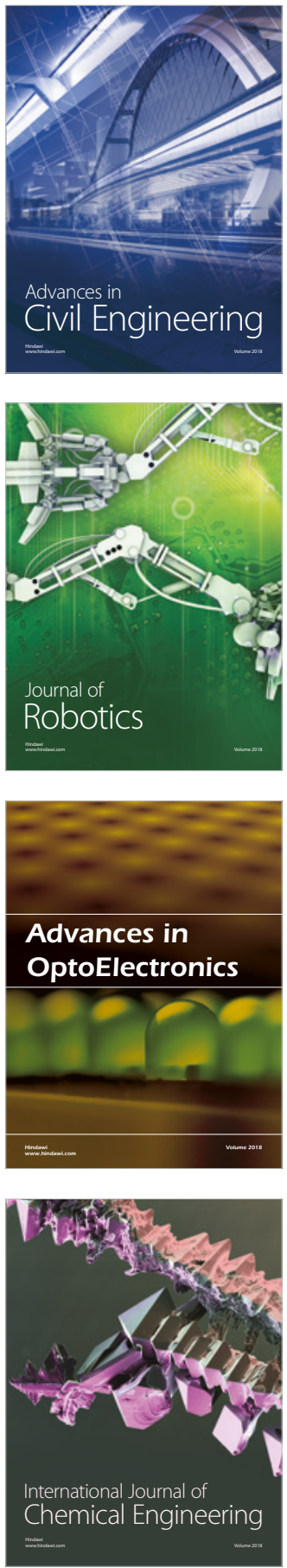

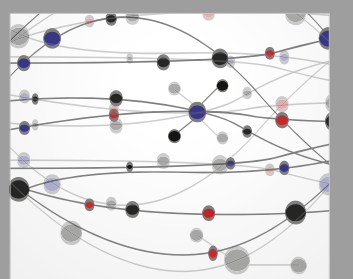

\section{Rotating \\ Machinery}

The Scientific World Journal

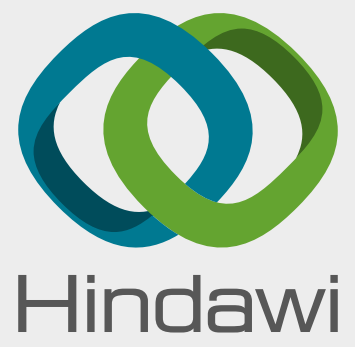

Submit your manuscripts at

www.hindawi.com
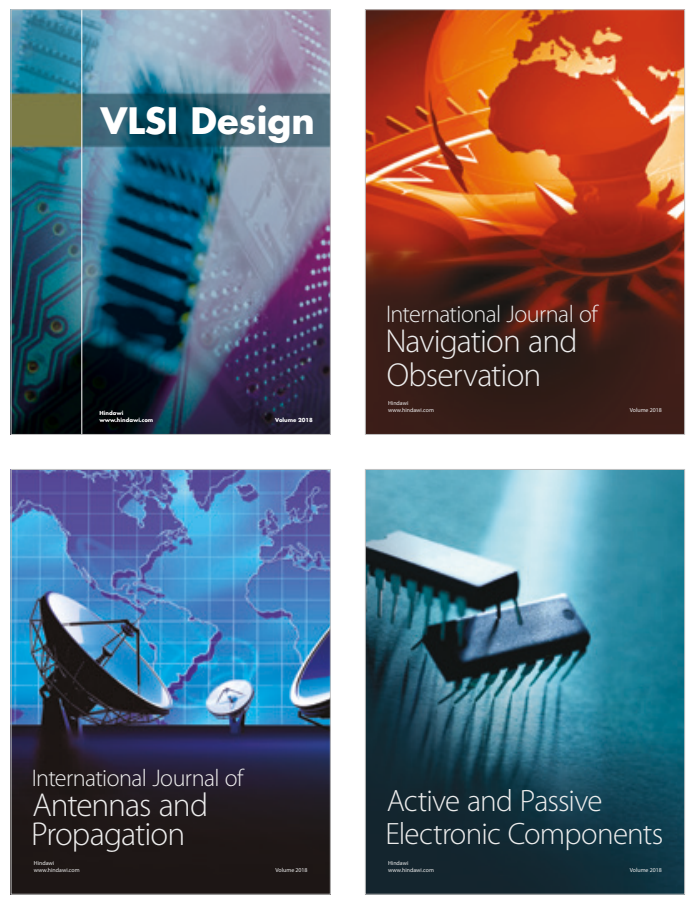
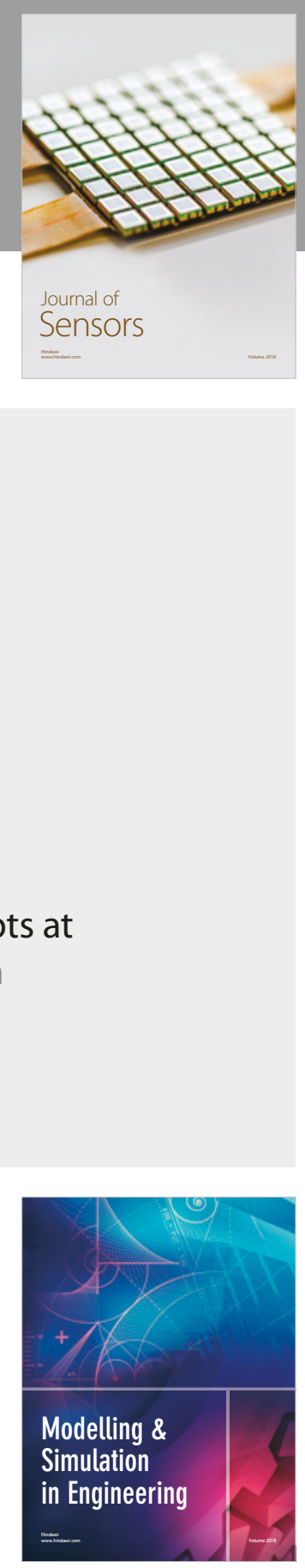

\section{Advances \\ Multimedia}
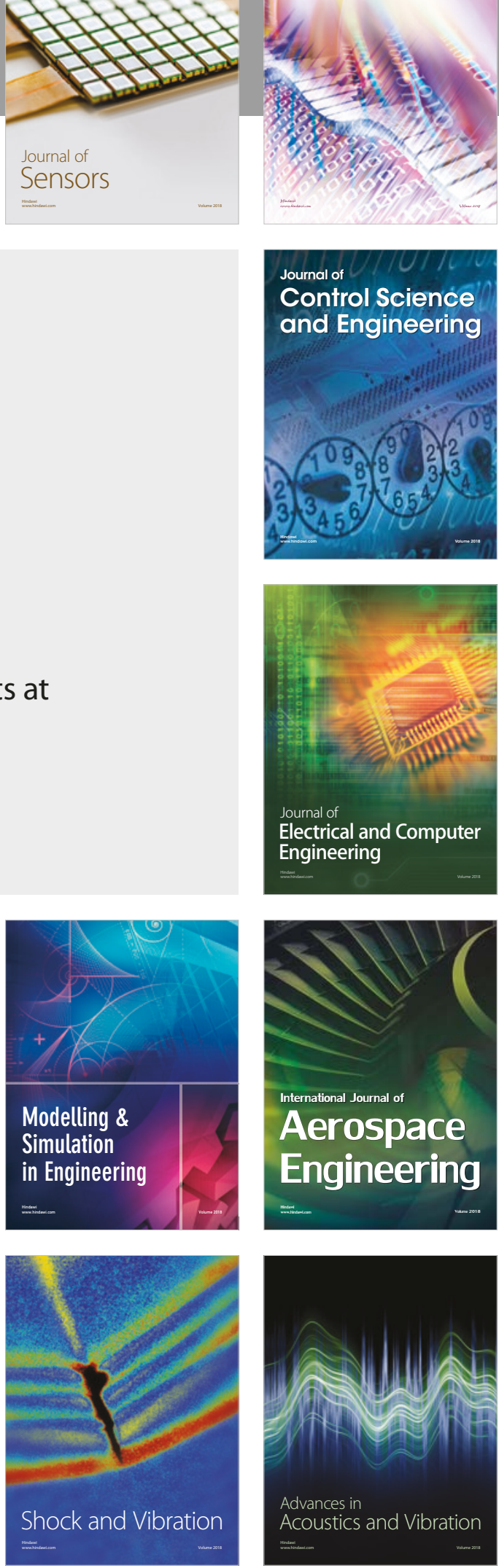